\title{
When to count your eggs: Is fecundity in Greenland halibut (Reinhardtius hippoglossoides W.)
}

\section{down-regulated?}

J. Kennedy $^{\mathrm{a}^{*}}$, A.C. Gundersen ${ }^{\mathrm{a}}$ and J. Boje ${ }^{\mathrm{b}}$

${ }^{\mathrm{a}}$ Møreforsking marin, PO Box 5075, Larsgården, N-6021, Ålesund, Norway. Tel: +47 70111640 Fax:

+47 70111601 Email: james@mfaa.no

${ }^{\mathrm{b}}$ DTU Aqua - National Institute of Aquatic Resources , DK-2920 Charlottenlund,

Denmark*Corresponding author

\begin{abstract}
Fecundity in several fish species is subject to down-regulation by atresia so if fecundity is estimated many months before spawning, this will be an overestimation of the realised fecundity (actual number of eggs spawned). In order to get accurate measurements of fecundity it is important to have knowledge on when potential fecundity (estimated fecundity at time of sampling) closely resembles the realised fecundity. Down-regulation of fecundity for Greenland halibut (Reinhardtius hippoglossoides W.) was assessed using fish caught off East Greenland 1998, 1999 and 2000. The fish caught in 1998 and 1999 were in an early and late stage of vitellogenesis respectively of the same maturation cycle. The fish caught in 2000 were also at an early stage of vitellogenesis. Fecundity decreased by $43 \%$ between early and late vitellogenesis. Fecundity in 1999 appeared to be the second lowest recorded for Greenland halibut but it is believed to be due to developmental stage rather than low productivity. There was no difference in fecundity between 1997 and 1998. It is believed that differences in fecundity between years only become apparent in late maturation as size during oocyte recruitment has a very large influence on fecundity. Neither Fulton's condition nor hepatosomatic index had any significant influence on fecundity.
\end{abstract}

Keywords: Greenland halibut, Reinhardtius hippoglossoides, fecundity, down-regulation, East Greenland

\section{Introduction}

Greenland halibut (Reinhardtius hippoglossoides W.) are a deep-water boreal species inhabiting large areas of the North-Atlantic. This species has the biological characteristics of a typical deep-water species: slow growth and late maturation. Even though Greenland halibut are an important commercial resource, knowledge of its reproductive biology is relatively sparse. Males mature at lengths of about $40-50 \mathrm{~cm}$ while females mature at about 50-60 $\mathrm{cm}$ (Morgan et al., 2003). They have a low fecundity (Gundersen et al., 1999) with very large eggs; developing oocytes have been documented as large as $2.4 \mathrm{~mm}$ (Gundersen et al., In review-a) and eggs collected in the field have been documented as large as $4.17 \mathrm{~mm}$ (Magnússon, 1977). Greenland halibut populations are known 
to exhibit a yearly maturation cycle with an extended spawning season; in the area around Iceland this runs from January until March (Morgan et al., 2003). Several studies have examined fecundity in Greenland halibut from several areas including the Northwest Atlantic (Lear, 1970; Bowering, 1980; Serebryakov et al., 1992; Junquera et al., 1999), North east Arctic (Gundersen et al., 1999; 2000) and Iceland (Gundersen et al., In review-b). However, sampling time in respect to time of year varies considerably between these studies.

In respect to fecundity development, fish are divided into two groups, indeterminate and determinate spawners (Hunter et al., 1992). The fecundity of indeterminate spawners is not fixed with a continuous recruitment of pre-vitellogenic oocytes to the developing pool of oocytes, even during spawning (Hunter et al., 1992). This is opposed to determinate spawners which recruit a batch of oocytes to the developing pool and then there is no more recruitment until the next maturity cycle (Hunter et al., 1992). It is now known that the fecundity in determinate spawners is not fixed but subject to down-regulation (Kurita et al., 2003; Thorsen et al., 2006; Kennedy et al., 2007). Downregulation is a process in which the fecundity is reduced to match the energy and/or food availability of the fish (Kjesbu and Witthames, 2007; Kennedy et al., 2008). Down-regulation happens by a process known as atresia which is the re-absorption of a developing oocyte (Hunter and Macewicz, 1985).

In order to calculate Stock reproductive potential (Trippel, 1999) it is essential to have accurate estimations of fecundity. The use of inaccurate values of fecundity can result in inaccurate perceptions on the state and productivity of a stock (Lambert, 2008). However, the collection of fecundity samples can be very difficult and expensive in terms of man hours, ship time and logistics. This is especially true when studying deepwater species which can spend many parts of the year under Ice covered seas so making their capture difficult. It is therefore important to know when the potential fecundity (standing stock of oocytes when sampled) is equal to, or very close to realised fecundity (actual number of eggs spawned). This is known to vary among species and depend on their life history. In herring (Clupea harengus) a large part of the down-regulation occurs during the autumn when herring switch from feeding to subsisting of stored reserves (Kurita et al., 2003). In plaice (Pleuronectes platessa) and cod (Gadus morhua) this is a gradual process happening over several months in response to reduced available energy (Kennedy et al., 2008; Witthames et al., 2009). In general it is considered that potential fecundity estimates taken very close to spawning will closely reflect the realised fecundity (Óskarsson and Taggart, 2006). Atresia has been witnessed previously in Greenland halibut and can be seen throughout the entire maturation process (Fedorov, 1971; Walsh and Bowering, 1981; Junquera et al., 1999; Tuene et al., 2002; Gundersen, 2003; Cooper et al., 2007) but this is generally of a low prevalence or intensity in fish in an advanced stage of ovary maturation. Over an extended period, continuous small levels of atresia could result in a substantial reduction in fecundity (Kurita et al. 2003). 
It is known that energy reserves can influence fecundity in several fish species i.e. fish of equal length but greater energy reserves will have a higher fecundity. Several proxies are commonly used for energy reserves in fishes such as Fulton's condition (which is a measure of weight at length) (see Nash et al., 2006) and hepatosomatic index (HSI) (Marshall et al., 1998). However Koops et al (2004) argues that weight is the most important decider of fecundity and that length based models of fecundity overinflate the variance in fecundity attributed to maternal condition. Weight can be a good measure of energy and protein reserves in fish which store these substances in the muscle; a high percentage of the total weight of fish is made up of muscle so changes in weight can reflect changes in available energy. It is known that the muscle is the main source of protein used for ovary development in plaice, a closely related species of flatfish (Dawson and Grimm, 1980).

In order to examine if there is a reduction in Greenland halibut fecundity during ovary development, fecundity was estimated for Greenland halibut during early and late stages of ovary development in East Greenland. This data was also compared to previously published data from 1997 (Gundersen et al., 2001). The effect of energy reserves on fecundity was also examined using Fulton's condition factor and HSI as proxies.

\section{Materials and methods}

\subsection{Sample collection}

The year, depth, area and number of fish sampled is summarised in Table 1. In 1998 ovaries were collected during a joint Norwegian - Greenland trawl survey during July and August in locality B (Fig. 1) in the waters off East Greenland. Trawling was conducted at depths 690-930m, using a commercial Greenland halibut trawl (mesh size 140mm). Ovaries which had began maturation (ovaries containing oocytes $>1 \mathrm{~mm}$ in diameter and visible to the naked eye) were sampled stratified to total length with a maximum of 15 fish in each $5 \mathrm{~cm}$ length group sampled. Ovaries were preserved in $3.6 \%$ buffered formaldehyde at sea.

In 1999 samples were collected from the German commercial trawl fishery in East Greenland waters in March (locality A and B, Fig. 1). The fishery was mainly carried out at depths 1280-1430m. Ovaries were collected randomly from the catches and frozen at sea. These were transported to the laboratory and thawed slowly at $4{ }^{\circ} \mathrm{C}$, before being preserved in $3.6 \%$ buffered formaldehyde. Most ovaries contained large oocytes with diameter of 2-4 mm. However, in some of the ovaries some of the oocytes had started hydration indicating spawning will start shortly. Ovaries containing hydrated oocytes were excluded from all analysis. The samples from the two areas were pooled as area did not have a significant effect on fecundity (see results). A total of 42 ovaries were analysed for fecundity.

In 2000, 112 ovaries were collected near Kap Bille Banke (locality A, Fig. 1) from Greenland halibut caught on longlines in the commercial fishing area during a joint Norwegian - Greenland 
survey in August at depths between 1100 and $1500 \mathrm{~m}$. Ovaries were collected in a similar manner to 1998.

From each female of which ovaries were taken, total length, total weight, gonad weight and liver weight was measured. The length range sampled was similar between years (see Table 2).

\subsection{Fecundity analysis}

Analyses of potential fecundity were carried out using the gravimetric method modified for Greenland halibut described by Gundersen et al. (1999; 2000). From each ovary four sub-samples of tissue of approximately $0.75-2.00 \mathrm{~g}$ were taken from the middle section of the right lobe of the ovary. Greenland halibut ovaries are known to be homogenous in oocyte packing density (Gundersen et al., 2001), hence samples were taken from only 1 location in the ovary. Of the 3 classes of oocytes found in this study only fully vitellogenic oocytes that will be spawned in the next spawning season (G1 oocytes) were counted. Classification of the oocytes is described in detail by Gundersen (2003). These oocytes appear dark when visualized under binocular microscope. Ovaries which did not contain vitellogenic oocytes were excluded from any analysis. Two sub-samples were counted and used in the fecundity estimates if the coefficient of variation of the estimates per unit ovary weight were below $5 \%$ for the two samples, otherwise all four samples were counted and analysed. The sub-sample count ranged from 300-500 G1 oocytes (Gundersen et al., 1999) depending on the maturity stage of the ovary. Gonads which have a leading cohort below $1000 \mu \mathrm{m}$ are possibly still recruiting oocytes so such samples were excluded from the analysis. Estimates of the fecundity of each individual female were obtained from the average of the raised sub-sample counts:

Fecundity $=\left(\sum \mathrm{C}_{\mathrm{n}} \mathrm{O} / \mathrm{W}_{\mathrm{n}}\right) / \mathrm{n}$

$\mathrm{C}_{\mathrm{n}}$ is the counted number of eggs in sub-sample $\mathrm{n}, \mathrm{O}$ is the ovary weight, $\mathrm{W}_{\mathrm{n}}$ is the sub-sample weight and $\mathrm{n}$ is the number of sub-samples. In order to obtain normality in data, estimation of the parameters describing fecundity of females as a function of length and weight was done on the $\log _{10}$-transformed model:

$\log F=a+b \log X$

$\mathrm{F}$ is the fecundity and $\mathrm{X}$ is the total length or weight of each female.

The oocyte packing density (number of oocytes per gram of ovary wet weight) within the ovary was calculated for each fish by dividing the fecundity by the weight of the gonads. This indicates the developmental stage of the ovaries as the density of oocytes is inversely proportional to the oocyte size which increases as the ovaries develop (Kjesbu 1994; Thorsen and Kjesbu 2001). Relative fecundity was calculated for each fish using the equation: 
Relative fecundity $=$ Fecundity/weight

\subsection{Indices}

Gonadosomatic index (GSI) gives the proportion of ovary with respect to the total weight. GSI was estimated using the equation :

$\mathrm{GSI}=\mathrm{GW}^{*} 100 / \mathrm{TW}$

GW is the gonad weight in grams, and TW is the total weight of the female in grams.

Hepatosomatic index (HSI) is an index showing the proportion of liver to the total body weight. HSI was estimated using the equation:

$\mathrm{HSI}=\mathrm{LV} * 100 / \mathrm{TW}$

LW is the liver weight in grams.

\section{Results}

Differences in GSI between years were tested for the log transformed values using ANOVA (model: $\log G S I=$ year + area). The year effect came out as significant with differences between all years (Tukey's post-hoc; $\mathrm{P}<0.001$ ). The highest GSI was in 1999 with an average of $13.6 \%$ (range from 2.0 to $27.9 \%$ ), followed by 2000 with an average of $3.3 \%$ (range from 1.8 to $5.6 \%$ ) and 1998 at $2.5 \%$ (range from 0.5 to 6.0\%) (Fig.2). GSI was positively correlated with length in 1998 and 2000 (Linear regression; $\mathrm{p}<0.05$ ) but not in 1999 (Linear regression $\mathrm{p}>0.05$ ). Neither Fulton's condition nor HSI differed between years (ANOVA; $>>0.05$ ).

Fecundity was positively correlated with length and the fecundity of an average 70, 80 and 90 $\mathrm{cm}$ fish was calculated for each year using the fecundity-length regressions (Fig.3 and Table 2). The fecundity-weight regressions had equal explanatory power to the fecundity length-regressions in 2 of the 4 years (table 2 and 3). In 1998, length was a better predictor of fecundity and in 2000 weight was a slightly better predictor of fecundity. When all the data was combined and analysed using ANCOVA with year as a grouping and length as covariate (model: Fecundity = year*length) the model had an $\mathrm{R}^{2}$ value of 0.81 ; this was not significantly different from when weight was used as the covariate, which gave an $\mathrm{R}^{2}$ value of 0.80 . Using multi-variate regression analysis, Fulton's condition and HSI were added to the regression but they did not increase the explanatory power of the model.

Differences in fecundity between years were tested using ANCOVA with length as a covariate (model: Fecundity $=$ year + area + length). The area effect was not significant $(p>0.05)$ but the year 
effect was significant ( $\mathrm{p}<0.05)$ (Table 4). Fecundity was not significantly different between 1997 and 1998 but both years were significantly different from 1999 and 2000. Fecundity in 1999 and 2000 was significantly different. Between August 1998 and March 1999 there was a reduction of 17, 41 and 45 $\%$ in fecundity of a 70,80 and $90 \mathrm{~cm}$ fish.

The oocyte packing density differed between years (ANOVA; $\mathrm{P}<0.0001$ ) with the highest values in 1998 and 1999 (486 and 493 respectively) which were not significantly different from each other (Tukey's post-hoc; p>0.05). The oocyte packing density in 1999 and 2000 was 337 and 79 respectively; these were significantly different from each other and from 1998 and 1999 (Tukey's post-hoc; $\mathrm{p}<0.0001$ ). Relative fecundity was positively correlated with oocyte packing density (Linear regression; $\mathrm{R}^{2}=0.23, \mathrm{p}<0.0001$ ) (Fig. 4 ) indicating that relative fecundity decreased as ovary development proceeded.

\section{Discussion}

Even though our samples were taken at two different sampling locations both sampling locations lie within the core area of distribution of Greenland halibut in the East Greenland area. Hydrographical conditions are fairly similar in the two areas of sampling, the water masses being dominated by the East Greenland polar current pressing down the warm Atlantic current (Hansen and Hermann, 1953) resulting in bottom temperatures of about $3-4^{\circ} \mathrm{C}$ in the sampling depth. As area exhibited no statistical significance on fecundity we therefore assumed that the sampling location did not influence the results.

A problem associated with estimating fecundity of fish which spawn their eggs in several batches is that individuals which have spawned one or more batch in the current season must be identified; if not the population fecundity will be under-estimated. It is currently unclear if Greenland halibut spawn their eggs in a single or several batches. Greenland halibut with fully hydrated eggs are rarely caught by trawlers or longliners, this is believed to either be due to spawning individuals being less susceptible to fishing gear, or to individuals having a very short spawning duration (i.e. very few batches). The ovaries of those that have been caught have been described as being completely filled with and containing only hydrated oocytes indicating that all eggs are spawned in a single batch (Gundersen et al, unpublished data). Due to this low incidence of capture and as Greenland halibut are likely to be total spawners, we consider the exclusion of fish which show any signs of hydration is sufficient to exclude any fish which are likely to have spawned any eggs in the current spawning season.

From the oocyte packing density and GSI we can infer that the fish in 1998 and 1999 are at different stages in the same maturity cycle and assumed to both be a representative sample of the population which would spawn in spring 1999; the fish were at a stage of early and late ovary development respectively. The fish caught in 2000 were also at a slightly more advanced stage in 
ovary development than the fish caught in 1998. This is evident from the higher GSI and lower oocyte packing density than the fish caught in 2000 .

The fecundity between August 1998 and March 1999, which are from fish at different stages in the same maturation cycle, shows quite a clear reduction in fecundity with a reduction of $45 \%$ in fish of $90 \mathrm{~cm}$. This is comparable to that seen in herring which may show a fecundity reduction of up to $56 \%$ (Kurita et al. 2003). The relative fecundity levelled out at an oocyte packing density of about 250-200 oocytes g ovary ${ }^{-1}$. This suggests that most of the down-regulation occurs during the early stage of ovary maturation which is supported by other studies which show that atresia is more prevalent and at higher intensities during early vitellogenesis (Junquera et al., 1999; Tuene et al., 2002; Gundersen, 2003). This shows that there is an 'atretic window' (Kurita et al. 2003) where atresia is most likely to occur; it is after this window in which estimates of fecundity should be made in order to reduce the error caused by down-regulation.

Fecundity was significantly different between 1998, 1999 and 2000 with a negative correlation between fecundity and ovary development. It cannot be exclude that difference between 1998 and 2000 is due to an inter-annual difference brought about by environmental conditions but is more likely to be, or at least in part, due to the down regulation of fecundity which, as mentioned, occurs most frequently during early vitellogenesis.

There appears to be some possible indications of down-regulation in fecundity in previous studies from the Southern Labrador area in the Western Atlantic. Fecundity estimated by Lear (1970), who sampled in March until October, were much higher than estimates taken by Bowering (Bowering, 1980) who sampled in October-November. Neither author gave GSI values so the developmental stage of their samples cannot be inferred. However, the difference in the month of sampling makes it reasonable to believe that the samples taken by Bowering had further developed gonads than the fish sampled by Lear (1970). However, this cannot be taken as direct evidence as these samples were taken in different years which may have an effect on the results.

The fecundity estimates from 1999 appear to be the one of the lowest values when compared to previous studies. A study by Magnússon (1977) is the only study which shows a lower fecundity, however that study was based on only 5 individuals. It is very difficult to compare fecundity estimates in different studies as time of sampling varies between them. It is also common among studies that samples were taken over many months (Bowering, 1980; Cooper et al., 2007), years (Junquera et al., 1999; Cooper et al., 2007) and sometimes over large geographical areas (Serebryakov et al., 1992) and the data is combined. Also for these cases no GSI data is provided and assessment of maturity stage is thus impeded. The month of sampling can help to give an indication of development stage but due to the extended spawning season in Greenland halibut and that the spawning season can vary between areas (Morgan et al., 2003), several fish caught in a single month can be in a very different development stage. Due to these limitations, we can only speculate that the low fecundity in Greenland halibut in East Greenland is due to development stage. In many studies, the sampling is 
carried out during the summer or autumn (Lear, 1970; Bowering, 1980; Cooper et al., 2007) so the ovaries probably would have been at an early stage of development thus giving a significant overestimation of fecundity.

There appears to be very little difference between length and weight in the predictive power of fecundity, this is different from what was found for Greenland halibut in the Barents Sea where weight gave a better relationship than length (Gundersen et al., 1999). It is also common for weight to be a better predictor of fecundity than length (Koops et al., 2004; Kennedy et al., 2007). However, the mechanisms as to why weight or length provides the best predictor are poorly understood. There was also no influence of energy reserves when Fulton's condition or HSI were used as proxies. This could be because Fulton's condition and HSI may be poor indicators of energy reserves in Greenland halibut. When protein or lipids become depleted they may be replaced by water (Templeman and Andrews, 1956) resulting in a decrease in the energy reserves of the fish, but without a significant change in the weight of the fish. If this occurs then this can make Fulton's condition a poor measure of energy reserves. HSI is probably not a good measure of energy reserves in Greenland halibut as the main store of lipids is likely to be the muscle. Greenland halibut muscle is known to be high in lipids (Møreforsking, unpublished data), and two other flatfish species (European plaice and Winter flounder) and are known to store the majority of their lipids in the muscle (Dawson and Grimm, 1980; Maddock and Burton, 1994).

There was no difference in fecundity between 1997 and 1998, this could be due to the fact that in some species fecundity differences only become apparent late in ovary maturation (Kennedy et al., 2007). This is because fecundity is strongly influenced by body weight during oocyte recruitment and early vitellogenesis resulting in no differences in a body size-fecundity relationship. The fecundity is then modified by down-regulation of atresia in response to available energy-reserves or food availability (Kennedy et al., 2008). A study by Junquera et al (1999) on Greenland halibut found no differences in fecundity over a period of 5 years. Their samples were taken in the summer, so presumably most of the fish were in early vitellogenesis when fecundity differences have not developed. There appears to be no study which compares fecundity estimates over several years taken close to the spawning time for Greenland halibut.

From our results it appears that that Greenland halibut down-regulate their fecundity, presumable in response to energy reserves or food availability. A large part of this down-regulation occurs during early vitellogenesis; however, due to only having two sampling points the full pattern is unclear. Further work is thus required with more frequent sampling of fish throughout the maturation cycle. Future studies should also publish the range of GSI values or ideally, oocyte diameter (which is not affected by fecundity), to give an indication of the developmental stage of the ovaries. This study also indicates that in order to obtain potential fecundity estimates which are close to the realised fecundity, fish should be sampled as close to spawning as possible. 


\section{References}

Bowering, W.R., 1980. Fecundity of Greenland halibut, Reinhardtius hippoglossoides (Walbaum), from Southern Labrador and Southeastern Gulf of St. Lawrence. J. Northw. Atl. Fish. Sci. 1, 39-43.

Cooper, D.W., Maslenikov, K.P., Gunderson, D.R., 2007. Natural mortality rate, annual fecundity, and maturity at length for Greenland halibut (Reinhardtius hippoglossoides) from the northeastern Pacific Ocean. Fish. Bull. 105, 296-304.

Dawson, A.S., Grimm, A.S., 1980. Quantitive seasonal changes in the protein, lipid and energy content of the carcass, ovaries and liver of adult female plaice. Pleuronectes platessa L. J. Fish Biol. $16,493-504$.

Fedorov, K.Y., 1971. The state of the gonads of the Barents Sea Greenland halibut (Reinhardtius hippoglossoides (Walbaum)) in connection with failure to spawn. J. Icthyol. 11, 673-682.

Gundersen, A.C., 2003. Sexual maturity, fecundity and nursery ground of Northeast Arctic Greenland halibut (Reinhardtius hippoglossoides (Walbum)). PhD Thesis, Department of Fisheries and Marine Biology, University of Bergen, Bergen, Norway. 203pp.

Gundersen, A.C., Hjörleifsson, E., Kennedy, J., 2009. Fecundity of Greenland halibut (Reinhardtius hippoglossoides W.) in the waters of Iceland. J. Northw. Atl. Fish. Sci.

Gundersen, A.C., Kjesbu, O.S., Nedreaas, K.H., Stene, A., 1999. Fecundity of Northeast Arctic Greenland halibut (Reinhardtius hippoglossoides). J. Northw. Atl. Fish. Sci. 25, 29-36.

Gundersen, A.C., Nedreaas, K.H., Kjesbu, O.S., Albert, O.T., 2000. Fecundity and recruitment variability of Northeast Arctic Greenland halibut during 1980-1998, with emphasis on 1996-1998. J. Sea Res. 44, 45-54.

Gundersen, A.C., Ronneberg, J.E., Boje, J., 2001. Fecundity of Greenland halibut (Reinhardtius hippoglossoides walbaum) in East Greenland waters. Fish. Res. 51, 229-236.

Gundersen, A.C., Stenberg, C., Fossen, I., Lyberth, B., Jørgensen, O.A., Boje, J., Kennedy, J., 2009. Sexual maturity cycle and spawning of Greenland halibut, $R$. hippoglossoides Walbum, in the Davis Strait. J. Fish. Biol.

Hansen, P.M. and F. Hermann, F., 1953. Fisken og havet ved Grønland. Medd. Danm. Fisk.-og havunders. N.S., 15: 128p.

Hunter, J.R., Macewicz, B.J., 1985. Rates of atresia in the ovary of captive and wild northern anchovy, Engraulis mordax. Fish. Bull. 83, 119-136.

Hunter, J.R., Macewicz, B.J., Lo, N.C.H., Kimbrell, C.A., 1992. Fecundity, spawning, and maturity of female Dover sole Microstomus pacificus, with an evaluation of assumptions and precision. Fish. Bull. 90, 101-128.

Junquera, S., Román, E., Paz, X., Ramilo, G., 1999. Changes in Greenland halibut growth, condition and fecundity in the Northwest Atlantic (Flemish Pass, Flemish Cap and Southern Grand Banks). J. Northw. Atl. Fish. Sci. 25, 17-28.

Kennedy, J., Witthames, P.R., Nash, R.D.M., 2007. The concept of fecundity regulation in plaice (Pleuronectes platessa) tested on three Irish Sea spawning populations. Can. J. Fish. Aquat. Sci. 64, 587-601. 
Kennedy, J., Witthames, P.R., Nash, R.D.M., Fox, C.J., 2008. Is fecundity in plaice (Pleuronectes platessa L.) down-regulated in response to reduced food intake during autumn? J. Fish Biol. 72, 78-92.

Kjesbu, O.S., 1994. Time of start of spawning in Atlantic cod (Gadus morhua) females in relation to vitellogenic oocyte diameter, temperature fish length and condition. J. Fish Biol. 45, 719-735.

Kjesbu, O.S. and Witthames, P.R., 2007. Evolutionary pressure on reproductive strategies in flatfish and groundfish: Relevant concepts and methodological advancements. J. Sea Res. 58, 23-34.

Koops, M.A., Hutchings, J.A., McIntyre, T.M., 2004. Testing hypotheses about fecundity, body size and maternal condition in fishes. Fish Fish. 5, 120-130.

Kurita, Y., Meier, S., Kjesbu, O.S., 2003. Oocyte growth and fecundity regulation by atresia of Atlantic herring (Clupea harengus) in relation to body condition throughout the maturation cycle. J. Sea Res. 49, 203-219.

Lambert, Y., 2008. Why should we closely monitor fecundity in marine fish populations? J. Northw. Atl. Fish. Sci. 41, 93-106.

Lear, W.H., 1970. Fecundity of Greenland halibut (Reinhardtius hippoglossoides) in the Newfoundland-Labrador Area. J. Fish. Res. Board. Can. 27, 1880-1882.

Maddock, D.M., Burton, M.P.M., 1994. Some effects of starvation on the lipid and skeletal muscle layers of the winter flounder, Pleuronectes americanus. Can. J. Zool. 72, 1672-1679.

Magnússon, J.V., 1977. Notes on the eggs and larvae of Greenland halibut at Iceland. ICES C.M. 1977/F:47, 6 pp.

Marshall, C.T., Kjesbu, O.S., Yaragina, N.A., Solemdal, P., Ulltang, O., 1998. Is spawner biomass a sensitive measure of the reproductive and recruitment potential of Northeast Arctic cod? Can. J. Fish. Aquat. Sci. 55, 1766-1783.

Morgan, M.J., Bowering, W.R., Gundersen, A.C., Høines, Å., Morin, B., Smirnov, O., Hjörleifsson, E., 2003. A comparison of the maturation of Greenland halibut (Reinhardtius hippoglossoides) from populations throughout the North Atlantic. J. Northw. Atl. Fish. Sci. 31, 99-112.

Nash, R.D.M., Valencia, A.H., Geffen, A.J., 2006. The origin of Fulton's condition factor-Setting the record straight. Fisheries 31, 236-238.

Óskarsson, G.J., Taggart, C.T., 2006. Fecundity variation in Icelandic summer-spawning herring and implications for reproductive potential. ICES. J. Mar. Sci. 63, 493-503.

Serebryakov, V.P., Chumakov, A.K., Tevs, I.I., 1992. Spawning stock, population fecundity and yearclass strength of Greenland halibut (Reinhardtius hippoglossoides) in the northwest Atlantic, 1969-88. J. Northw. Atl. Fish. Sci. 14, 107-113.

Templeman, W., Andrews, G.L., 1956. Jellied condition in the American plaice Hippoglossoides platessoides (Fabricius). J. Fish. Res. Board. Can. 13, 147-182.

Thorsen, A., Marshall, C.T., Kjesbu, O.S., 2006. Comparison of various potential fecundity models for north-east Arctic cod Gadus morhua, L. using oocyte diameter as a standardizing factor. J Fish Biol J Fish Biol 69, 1709-1730.

Trippel, E.A., 1999. Estimation of stock reproductive potential: History and challenges for Canadian Atlantic gadoid stock assessments. J. Northw. Atl. Fish. Sci. 25, 61-81. 
Tuene, S., Gundersen, A.C., Emblem, W., Fossen, I., Boje, J., Steingrund, P., Ofstad, L.H., 2002. Maturation and occurrence of atresia in oocytes of Greenland halibut (Reinhardtius hippoglossoides W.) in the waters of East Greenland, Faroe Islands and Hatton Bank. In: Gundersen, A.C. (Ed.), Reproduction of West-Nordic Greenland halibut. Tema Nord, Copenhagen, Denmark. pp. 73-96.

Walsh, S.J., Bowering, W.R., 1981. Histological and visual observations on oogenesis and sexual maturity in Greenland halibut. NAFO Sci. Coun. Studies 1, 71-75.

Witthames, P.R., Thorsen, A., Greenwood, L.N., Saborido-Ray, F., Dominguen, R., Murua, H., Korta, M., Kjesbu, O.S., 2009. Advances in fecundity methodology applied to some marine fishes. Fish Bull, 107: 148-164. 
Table 1. Details of the year, month, depth, area (see Fig. 1) and number of fecundity samples taken for Greenland halibut in East Greenland.

$\begin{array}{lllll}\text { Year } & \text { Month } & \text { Depth } & \text { Area } & \text { N } \\ 1998 & \text { July-August } & 690-930 & \text { B } & 74 \\ 1999 & \text { March } & 1280-1430 & \text { A+B } & 42 \\ 2000 & \text { August } & 1100-1500 & \text { A } & 112\end{array}$


Table 2. The fecundity-length relationships ( $F=$ fecundity, $T L=$ total length) for Greenland halibut caught off East Greenland showing the number of fish sampled (n), $R^{2}$ of the relationship, the total length (cm) of the smallest (Min TL) and largest fish (Max TL) sampled, and the fecundity of the average 70,80 and $90 \mathrm{~cm}$ fish as predicted from the equation.

Fecundity (thousands)

$\begin{array}{lllllllll}\text { Year } & \text { relationship } & \mathbf{n} & \mathbf{R}^{2} & \text { Min TLMax TL } & \mathbf{7 0} & \mathbf{8 0} & \mathbf{9 0} \\ 1997 * & \mathrm{~F}=5.16 \times 10^{-6} * \mathrm{TL}^{3.751} & 112 & 0.81 & 63 & 110 & 43 & 71 & 110 \\ 1998 & \log \mathrm{F}=3.92 * \log \mathrm{TL}-5.62 & 74 & 0.71 & 56 & 96 & 41 & 69 & 110 \\ 1999 & \log \mathrm{F}=2.73 * \log \mathrm{TL}-3.55 & 42 & 0.76 & 55 & 100 & 34 & 41 & 61 \\ 2000 & \log \mathrm{F}=3.30 * \log \mathrm{TL}-4.52 & 112 & 0.72 & 57 & 107 & 37 & 58 & 85 \\ \text { *from Gundersen et al } 2001 & & & & & & \end{array}$


Table 3. The fecundity-weight relationships ( $F=$ fecundity, $W=$ total weight) for Greenland halibut caught off East Greenland showing the number of fish sampled (n), $R^{2}$ of the relationship and the total weight (g) of the smallest (Min W) and largest fish (Max W) sampled.

\begin{tabular}{llllll} 
Year & relationship & $\mathbf{n}$ & $\mathbf{R}^{2}$ & \multicolumn{2}{c}{ Min W Max W } \\
$1997 *$ & $\mathrm{~F}=7.16 \times 10^{-3} * \mathrm{~W} 1.066$ & 112 & 0.81 & 2690 & 17220 \\
1998 & $\log \mathrm{F}=1.07 * \log \mathrm{W}-2.18$ & 74 & 0.57 & 1254 & 11250 \\
1999 & $\log \mathrm{F}=0.85 * \log \mathrm{W}-1.57$ & 42 & 0.76 & 1775 & 11235 \\
2000 & $\log \mathrm{F}=1.00 * \log \mathrm{W}-1.98$ & 112 & 0.77 & 1840 & 16620 \\
$*$ from Gundersen et al 2001 & & & &
\end{tabular}


Table 4. The p values of the ANCOVA for log transformed fecundity between years.

$1997 \quad 1998 \quad 1999$

1997

$1998>0.05$

$1999<0.001<0.001$

$2000<0.001<0.001<0.001$ 


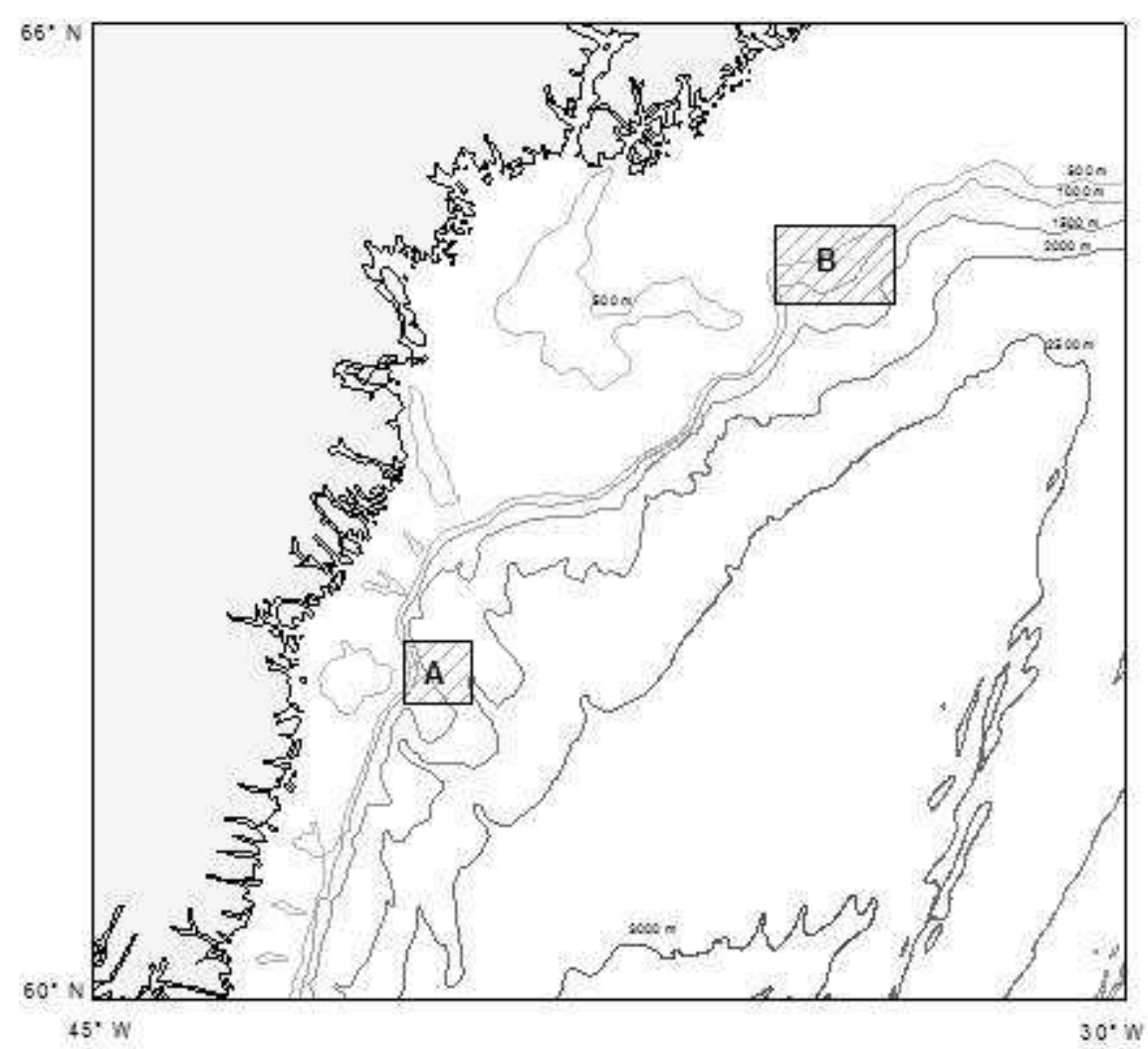

Fig. 1 Localities of sampling of Greenland halibut ovaries in 1998-2000. 


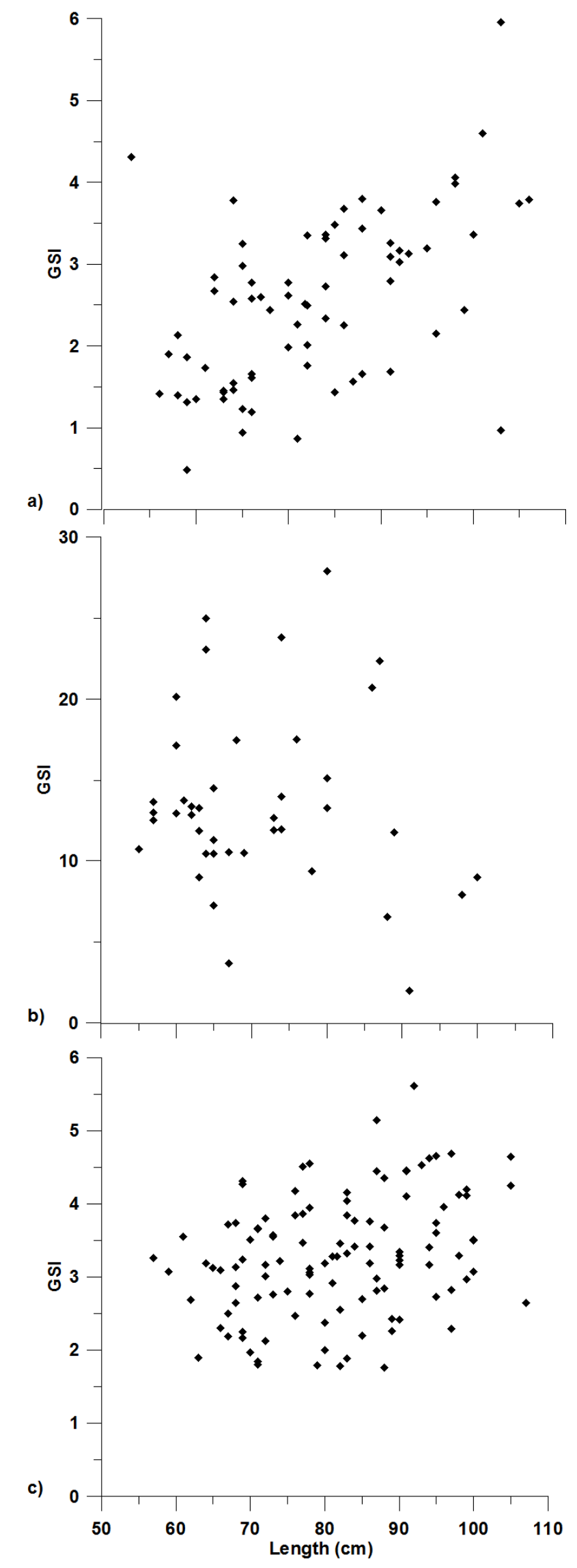

Fig. 2 Gonadosomatic index (GSI) values plotted against length for Greenland halibut caught in a) 1998, b) 1999 and c) 2000. Note that the scale on the x-axis differs between graphs. 


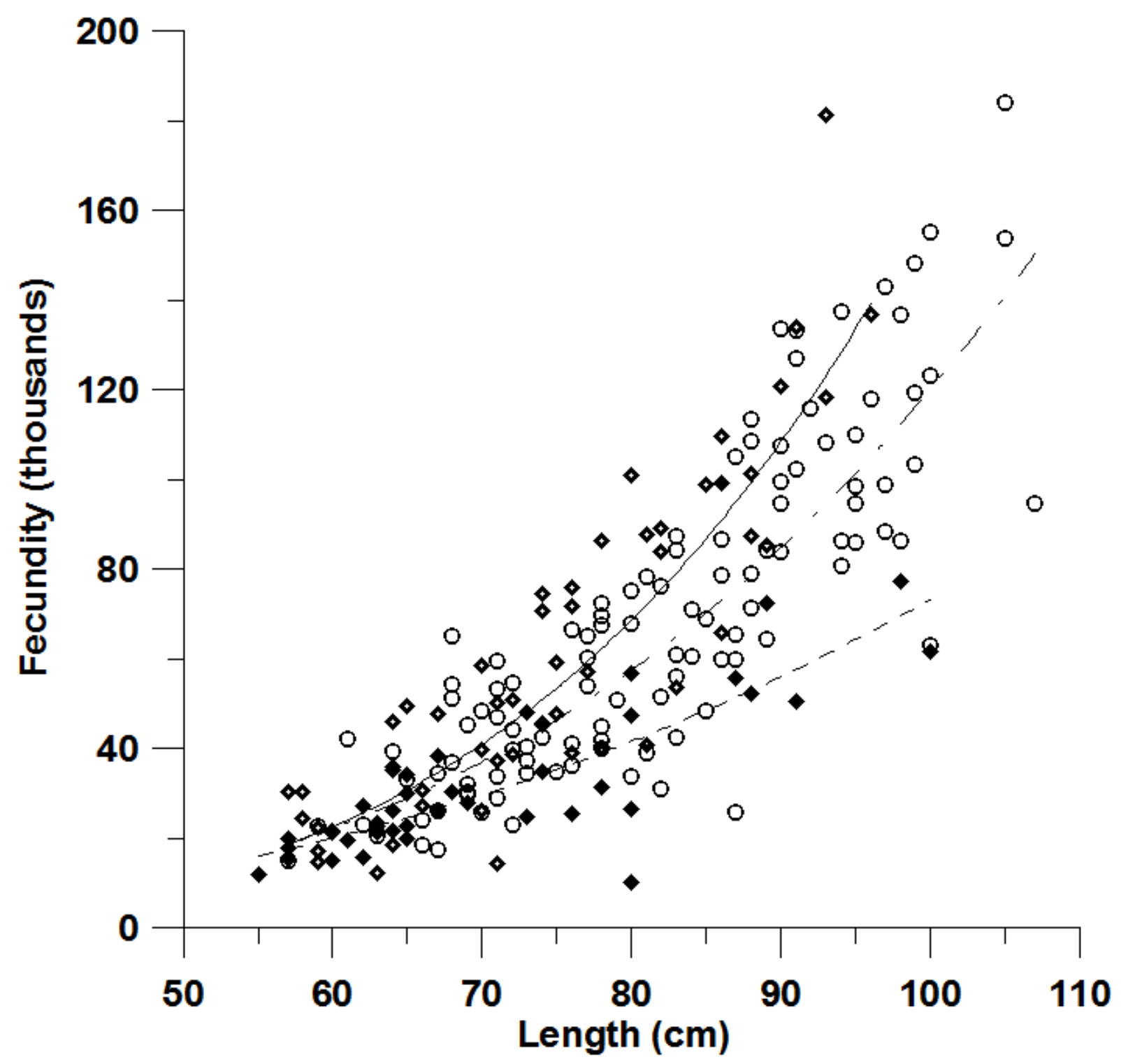

Fig. 3 Fecundity-length relationship in $1998(\diamond), 1999(\circ)$ and $2000(\diamond)$ with power regression lines for 1998 (solid line), 1999 (dashed line) and 2000 (dash-dot line). 


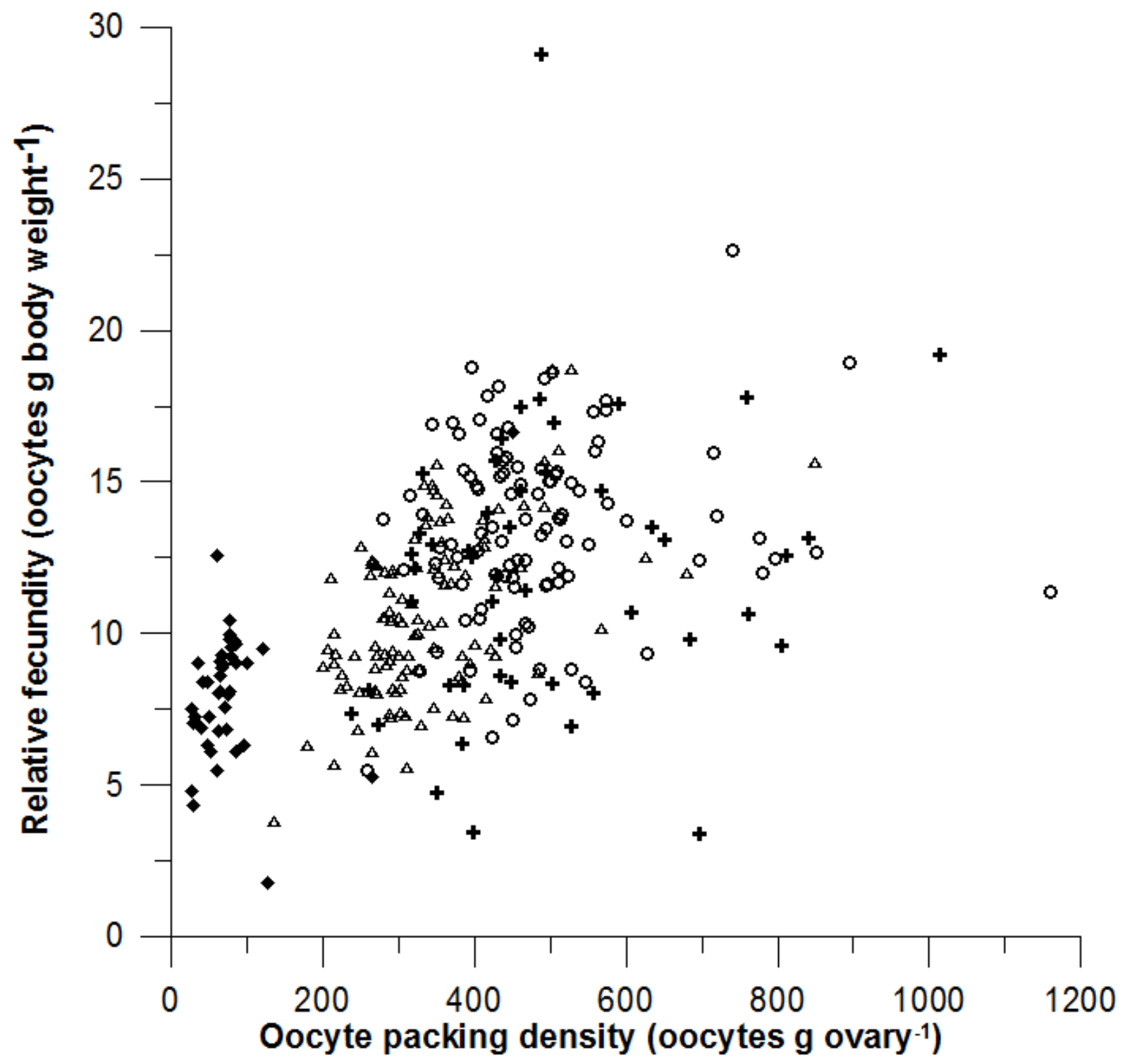

Fig. 4 Relationship between relative fecundity and the oocyte packing density of the ovary for Greenland halibut caught in the waters in East Greenland. 